\title{
TÉCNICA DA PEROXIDAÇÃO PARA A DETERMINAÇÃO DE METIONINA EM AMOSTRAS DERIVADAS DE ENSAIOS DE DIGESTIBILIDADE DO TRIGO E SEUS SUBPRODUTOS EM FRANGOS DE CORTE
}

\author{
The peroxidation technique for methionine determination in derived samples of digestibility assays \\ of the wheat and its by-products in broilers chickens
}

\author{
Leonardo Boscoli Lara ${ }^{1}$, Flávia Maria de Oliveira Borges ${ }^{2}$, Eloísa de Oliveira Simões Saliba ${ }^{3}$, \\ Carlos Eduardo do Prado Saad ${ }^{4}$, Edgar Aleixo Teixeira ${ }^{5}$
}

\begin{abstract}
RESUMO
Realizou-se um experimento com excreta de aves usando comparar técnicas de hidrólise de aminoácidos com ou sem peroxidação prévia para determinação de metionina. O delineamento experimental foi inteiramente ao acaso, em esquema fatorial 2 x 4 x 8, (métodos x tratamentos x alimentos) com três repetições. Sete alimentos oriundos do trigo e uma ração-referência foram utilizados nos quatro tratamentos. Os dois primeiros tratamentos foram baseados na metodologia tradicional de consumo à vontade e utilizou-se o método da alimentação forçada com aves intactas e aves cecectomizadas nos tratamento 3 e 4, respectivamente. Somente a técnica de peroxidação da amostra com ácido perfórmico seguida de hidrólise apresentou resultados confiáveis na análise de biodisponibilidade e conteúdo de metionina do trigo e seu subprodutos.
\end{abstract}

Termos para indexação: Aves, metodologia analítica, hidrólise ácida, peroxidação, trigo.

\begin{abstract}
One experiment was conducted with broiler chickens, for evaluation of metabolizable methionine and its levels in the wheat and some of its products, comparing two analyses techniques of methionine determination; hydrolyze and peroxidation with performic acid before hydrolyze. The broilers were randomly distributed in factorial outline $2 \times 4 \times 8$, (methods $\mathrm{x}$ treatments $\mathrm{x}$ feeds) with three repetitions. Seven feeds by-products of wheat grain were used in the four treatments. The first two treatments were set in the traditional methodology of ad libitum consumption and in the treatments three and four, the method of forced feeding was used. The treatment four were tested in the caecectomised chickens. The results of this experiment suggested that only the peroxidation with performic acid before hydrolyze showed good result in measure metabolizable methionine and its levels of wheat and its by-products.
\end{abstract}

Index terms: birds. methionine, hydrolisis, peroxidation, analytical methodology, wheat.

(Recebido para publicação em 6 de abril de 2004 e aprovado em 10 de março de 2005)

\section{INTRODUÇÃO}

Os aminoácidos têm sido determinados por hidrólise ácida e posteriormente analisados por HPLC, baseados nos trabalhos de Moore et al. (1958) e Schram et al. (1953), citados por Llames \& Fontaine, (1994). A preparação da amostra por esse método segue os trabalhos de Bech-Andersen (1979) e Rudemo (1980), citados por Llames \& Fontaine (1994). Segundo esses autores, parte da metionina é perdida pelo método de hidrólise ácida. Para evitar essa perda, deve-se peroxidar a amostra com ácido perfórmico antes de hidrolisá-la. Este é um método mais trabalhoso, demorado e caro. Ao utilizar a hidrólise convencional na determinação da biodisponibilidade de metionina, Kessler et al. (1981) e Muztar \& Slinger (1977) utilizaram a hipótese de que a perda da metionina é muito pequena e ocorre tanto no alimento quanto na excreta, portanto, o coeficiente de biodisponibilidade não seria afetado.

Para determinar cistina e metionina (BECHANDERSEN, 1990, citados por LLAMES \& FONTAINE, 1994) utiliza-se uma técnica na qual se pesa o equivalente a $10 \mathrm{mg}$ de nitrogênio de cada amostra previamente moída a $0,25 \mathrm{~mm}$. Adiciona-se a frio $5 \mathrm{~mL}$ de ácido perfórmico por amostra, preparado logo antes de sua utilização a partir de $0,5 \mathrm{~mL}$ de peróxido de hidrogênio a 30\% e 4,5 ml de ácido fórmico a $88 \%$. As amostras são levadas ao banho de gelo por 16 horas.

\footnotetext{
1. Médico Veterinário, MSc - Estudante de Doutorado da Universidade Federal de Lavras/UFLA - Caixa Postal 3037 - $37.200-000$ - Lavras, MG leovet@ig.com.br

2. Medica Veterinária, M.Sc. - Dra em Nutrição Animal - Universidade Federal de Lavras/UFLA - borgesvet@ufla.br

3. Químico, M.Sc. PhD Nutrição Animal - Universidade Federal de Minas gerais/UFMG.

4. Zootecnista, MSc. - Dr Nutrição Animal - Fundação Zoobotânica de Belo Horizonte.

5. Médico Veterinário - Estudante de Doutorado da Universidade Federal de Minas Gerais/UFMG.
} 
Dessa maneira, a cistina é convertida a ácido cistéico e a metionina à metionina sulfônica, que são compostos resistentes à hidrólise, podendo ser mensurados por cromatografia. Depois do banho de gelo são adicionados $0,84 \mathrm{~g}$ de metabissulfito de sódio por amostra para decompor o excesso de ácido perfórmico, formando dióxido de enxofre que será liberado durante 15 minutos. A amostra é então submetida à mesma hidrólise ácida descrita anteriormente. A tirosina é destruída pela peroxidação e o triptofano na hidrólise, portanto, não podem ser determinados por essa técnica.

Spindler et al. (1984), citados por Llames \& Fontaine (1994) utilizaram técnica semelhante à anterior. A peroxidação é feita da mesma forma, porém o excesso de ácido perfórmico é neutralizado com a adição de $0,70 \mathrm{~mL}$ de ácido hidrobromídrico a $48 \%$, formando bromo. As amostras permanecem no banho de gelo por mais 30 minutos para liberar o bromo e então são transferidas para o rotavapor - que deve estar na temperatura ambiente - até a solução passar da cor laranja para amarelo-claro. A hidrólise também se procede da mesma maneira à das técnicas anteriores. O triptofano é destruído pela hidrólise, a tirosina pela peroxidação e a fenilalanina e a histidina reagem com o bromo e também não podem ser determinadas por essa técnica.

Llames \& Fontaine (1994) submeteram amostras de rações inicial e de engorda de frangos, farinha de peixe e farinha de aves , a 23 laboratórios que analisam aminoácidos pelo metabissulfito de sódio. A variação da repetibilidade e reprodutibilidade da metionina em relação ao desvio-padrão foi de $1,13 \%$ a 5,56\% e 7,55\% a $11,97 \%$ respectivamente, com oito resultados descartados por apresentarem valores extremamente fora do padrão. Os valores de metionina na ração inicial variaram de $0,45 \%$ a $0,65 \%$ na ração de engorda de frangos, de $0,49 \%$ a $0,75 \%$ na ração inicial; de 0,15 a 0,23 no milho; de $1,3 \%$ a $1,92 \%$ na farinha de peixe e de $0,96 \%$ a $1,53 \%$ na farinha de aves.

Amostras das mesmas rações e ingredientes foram enviadas a outros 16 laboratórios que analisaram os aminoácidos pelo ácido hidrobromídrico. A repetibilidade e a reprodutibilidade da metionina foram de $1,27 \%$ a $2,52 \%$ e $4,44 \%$ a $13,68 \%$, respectivamente, com 10 resultados descartados por apresentarem valores extremamente fora do padrão. Os valores de metionina variaram de $0,43 \%$ a $0,69 \%$ na ração de engorda de frangos; de $0,27 \%$ a $0,82 \%$ na ração inicial; de 0,14 a 0,25 no milho; de $1,03 \%$ a $2,1 \%$ na farinha de peixe e de $0,82 \%$ a $1,74 \%$ na farinha de aves.

Os resultados de metionina obtidos por ambos os métodos variaram bastante. Se for consultada uma tabela de valores nutricionais dos alimentos, o valor de metionina da mesma farinha de peixe, por exemplo, pode variar de $0,82 \%$ a $1,92 \%$.

Gehrke et al. (1985), citados por Williams (1994), mostraram que o tempo de hidrólise pode variar de acordo com a temperatura em que a amostra é submetida, por exemplo, $\mathrm{HCl} 6 \mathrm{~N}$ a $145^{\circ} \mathrm{C}$ por 4 horas possui o mesmo resultado que $\mathrm{HCl} 6 \mathrm{~N}$ à $110^{\circ} \mathrm{C}$ por 24 horas. Segundo Williams (1994), o tempo de hidrólise de 48 a 72 horas é recomendado para isoleucina e valina, desde que sejam resistentes à hidrólise; mas a hidrólise prolongada degrada a treonina e a serina. Chiou \& Wang (1989, 1990), citados por Williams (1994) utilizaram ácido metanosulfônico $4 \mathrm{~N}$ por $180^{\circ} \mathrm{C} \pm 5^{\circ} \mathrm{C}$ por 5 a 10 minutos em microondas comerciais e encontraram resultados confiáveis para metionina, cistina e triptofano, sendo que a exposição de 4 minutos ou menos levava ao aparecimento de picos desconhecidos. Cowie \& Hedges (1992), citados por Williams (1994) observaram que os melhores resultados na determinação de metionina foram conseguidos a $150^{\circ} \mathrm{C}$, durante 70 minutos.

Slump \& Boss (1985) utilizaram a técnica de peroxidação com ácido perfórmico e sua neutralização com ácido hidrobromídrico em um padrão de caseína, no qual se fez variar a concentração de íons cloreto. Valores de metionina mais baixos foram encontrados à medida que se aumentava a concentração desses íons, chegando ao valor $20 \%$ mais baixo de metionina na proporção de $20 \mathrm{mg}$ de cloreto de sódio para $3 \mathrm{mg}$ de metionina. Para corrigir a interferência dos íons cloreto os autores propuseram a adição de $50 \mathrm{~mL}$ de água deionizada para cada $20 \mathrm{~mL}$ de ácido perfórmico; entretanto, a água deionizada adicionada interfere na dosagem de cistina.

Com este trabalho objetivou-se avaliar a biodisponibilidade da metionina no trigo e seus subprodutos em várias metodologias de determinação de biodisponibilidade de aminoácidos in vivo, por meio da técnica de peroxidação com ácido perfórmico seguida de hidrólise, comparando os valores obtidos com aqueles encontrados por Borges (1999), pela técnica de hidrólise ácida.

\section{MATERIAL E MÉTODOS}

O experimento foi desenvolvido nas dependências do Departamento de Zootecnia da Escola de Veterinária da Universidade Federal de Minas Gerais (UFMG). Uma ração-referência e sete alimentos-teste, constituídos de produtos oriundos do trigo, foram utilizados em todos os métodos: trigo integral moído (TIM), gérmen de trigo (GT), farinha de trigo clara (FTC), farinha 
de trigo escura (FTE), farelo de trigo para uso humano (FTH), farelo de trigo para uso animal (FTA) e farelo de trigo grosso (FTG).

Na etapa 1 foram utilizados 360 pintos de corte, da linhagem "Hubbard", machos, com 14 dias de idade. Trezentos e vinte pintos foram distribuídos ao acaso em oito tratamentos, com quatro repetições de 10 aves cadauma. Os 40 pintos restantes foram empregados em um tratamento extra, ficando em jejum por 72 horas, a fim de avaliar as perdas endógenas e metabólicas, de modo a determinar um fator de correção para estimar a matéria seca metabolizável verdadeira dos alimentos. Os pintos foram alojados em gaiolas metálicas e utilizou-se o método tradicional de coleta total de excreta, com os pintos recebendo a ração-referência até a idade de 13 dias, quando se iniciou o experimento. $\mathrm{O}$ trabalho foi conduzido no período de oito dias. As aves foram pesadas no início e no final do experimento e passaram por um período de adaptação à dieta de três dias, imediatamente anterior ao período de coleta experimental.

Os alimentos testados substituíram $40 \%$ (base da matéria natural) de uma dieta-referência formulada a base de milho moído, farelo de soja, óleo de soja e mistura vitamínico-mineral, constituindo assim, sete dietas experimentais. A dieta-referência constituiu um tratamento e foi calculada segundo recomendações de Rostagno et al. (1985). As rações testadas foram consumidas à vontade durante oito dias, em regime de luz de 23 horas.

As excretas foram coletadas diariamente em intervalos de 12 horas durante cinco dias, pesadas, homogeneizadas ao final do experimento quando retirou-se uma alíquota de $500 \mathrm{~g}$ para secagem em estufa de ventilação forçada. Registraram-se as quantidades de raçãoteste ingeridas por unidade experimental. A matéria seca (MS) foi determinada em estufa a $105^{\circ} \mathrm{C}$ e $55^{\circ} \mathrm{C}$ segundo Cunniff (1995) para as amostras de excreta.

As dietas e o delineamento experimental da etapa 2 foram as mesmas da etapa 1 , exceto que a unidade experimental foi composta por cinco aves, com 39 dias de idade, alojadas em uma mesma gaiola, constituindo uma repetição. Foram utilizadas 180 aves, das quais 160 foram distribuídas aleatoriamente entre os oito tratamentos, com quatro repetições cada e as 20 restantes constituíram o tratamento extra, também com a finalidade de avaliação das perdas endógenas.

Na etapa 3, foram utilizados 72 aves oriundas dos ensaios anteriores em delineamento experimental inteiramente ao acaso. Sessenta e quatro aves foram distribuídas em oito tratamentos e quatro repetições, com duas aves por unidade experimental, utilizando-se o método da alimentação forçada descrito por Sibbald (1976). Igual aos métodos anteriores, o tratamento extra (duas aves por repetição $\mathrm{x}$ quatro repetições = oito aves) foi utilizado para estimar as perdas endógenas e metabólicas.

O período experimental foi de quatro dias, obedecendo ao seguinte cronograma: todas as aves foram submetidas ao jejum de 30 horas para esvaziamento completo do trato gastrintestinal ; após o jejum foram forçadas a ingerir 25 gramas dos alimentos-teste de uma única vez. Diferente dos métodos anteriores, foram utilizados os alimentos puros, sem fração de substituição. As aves do tratamento extra foram deixadas em jejum por mais 48 horas para determinação das perdas metabólicas e endógenas. As aves tiveram toda a região da cloaca previamente depenada para evitar aderência da excreta.

A coleta de excreta foi total, de 12 em 12 horas, até completar o período exato de 48 horas para todas as aves, inclusive as em jejum. No final do experimento foram agrupadas por repetição e homogeneizadas para futuras análises.

A etapa 4 foi realizada em quatro dias, utilizando-se aves previamente cecectomizadas cirurgicamente, segundo Pupa et al. (1998), em delineamento semelhante à etapa 3.

Foram utilizadas 36 aves com 12 semanas de idade e peso médio de $3,5 \mathrm{~kg}$. Trinta e duas aves foram distribuídas em oito tratamentos com quatro repetições. As quatro aves restantes foram deixadas em jejum durante todo o período experimental, para obtenção das perdas metabólicas e endógenas. A unidade experimental foi composta de apenas uma ave, e as 32 aves foram forçadas a ingerir 25 gramas dos alimentos experimentais puros, semelhante à etapa 3 .

As análises da metionina foram feitas por cromatografia líquida de alta eficiência no laboratório de nutrição animal da Escola de Veterinária da UFMG, nos alimentos puros, na ração-referência, rações teste e excretas.

A metionina foi determinada por duas técnicas com adaptações:

Técnica 1 : Hidrólise ácida da amostra com ácido clorídrico $6 \mathrm{~N}$, com leitura em cromatógrafo SHIMADZU-10A, acoplado a detector de fluorescência, com coluna de troca iônica (catiônica). A reação pós-coluna foi feita com ortoftalaldialdeído (OPA).

Técnica 2: Peroxidação com ácido fórmico 88\% e ácido perfórmico $38 \%$, neutralizados com ácido bromídico 48\% antes da hidrólise com ácido clorídrico $6 \mathrm{~N}$. A leitura foi semelhante à técnica anterior. 
Para validar a eficiência da técnica foi realizada a peroxidação seguida de hidrólise ácida do padrão de metionina com $99 \%$ de pureza e cistina com $100 \%$ de pureza, obtendo-se uma taxa de recuperação de 95,72\% para a metionina e $51,27 \%$ para a cistina (o resultado da taxa de recuperação impossibilitou a utilização dos valores de cistina obtidos neste trabalho).

Também foi feita a hidrólise ácida do mesmo padrão de cistina e metionina descrita anteriormente, em triplicata, encontrando taxas de recuperação de 45,33\%; $59,47 \%$ e $63,14 \%$ para a metionina e valores praticamente nulos para cistina.

Para a comparação estatística entre hidrólise ácida e peroxidação, o delineamento experimental foi inteiramente ao acaso, em esquema fatorial 2 x 8, (métodos $\mathrm{x}$ alimentos) com três repetições, em cada uma das quatro etapas diferentes, portanto o esquema fatorial foi $2 \mathrm{x}$ $8 \times 4$. As médias foram comparadas pelo teste $\mathrm{F}$.

As metodologias de cálculos dos coeficientes de metionina digestível aparente e verdadeira dos alimentos foram semelhantes as descritas por Albino (1991).

\section{RESULTADOS E DISCUSSÃO}

Na Tabela 1 constam os dados de composição em metionina dos alimentos testados (base matéria seca).

Os valores de metionina diferiram $(\mathrm{P}<0,05)$ entre as técnicas analíticas, e essa diferença foi muito variável segundo os alimentos testados. Esse fato, aliado às taxas de recuperação da metionina das técnicas utilizadas neste trabalho, mostra que não se pode confiar nos valores de metionina dos alimentos quando se utiliza a hidrólise sem a peroxidação prévia.

Foram encontrados valores mais altos de metionina na ração-referência $(\mathrm{P}, 0,05)$ quando se utilizou a hidrólise convencional em comparação com a peroxidação. Isso pode ocorrer devido a dois fatores: a metioni- na, pode ser quebrada na hidrólise em outros compostos que poderão ser medidos pelo cromatógrafo somados à metionina e nesse caso a ração-referência pode ter maior quantidade desses compostos; ou os íons cloreto presentes na ração-referência, suplementada com cloreto de sódio, interferiram na peroxidação da metionina que, segundo Slump \& Boss (1985), pode levar a uma redução de até $20 \%$ nos resultados das análises.

No trigo integral moído valores semelhantes $(\mathrm{P}>0,05)$ foram obtidos pelas duas técnicas, muito provavelmente por interferência dos constituintes do trigo os quais protegem a metionina na hidrólise ácida.

No germe de trigo, na farinha de trigo escura e no farelo de trigo para uso animal foram encontrados valores estatisticamente diferentes $(\mathrm{P}<0,05)$, até quase duas vezes maiores, ao ser utilizada a hidrólise precedida de peroxidação, quando comparada aos valores obtidos somente por hidrólise convencional. $\mathrm{O}$ germe de trigo apresentou maior teor de metionina $(\mathrm{P}<0,05)$ que a ração-referência quando se utilizou a peroxidação. O mesmo não ocorreu ao se utilizar a hidrólise convencional $(\mathrm{P}>0,05)$.

As amostras apresentaram valores de metionina diferentes $(\mathrm{P}<0,01)$ de acordo com a técnica analítica, e ao compararmos os valores de metionina dos alimentos temos uma média de $35 \%$ de perda de metionina pela hidrólise convencional com desvio-padrão de 14,33 e ao compararmos os valores de metionina das excretas temos uma média de $70 \%$ de perda de metionina pela hidrólise convencional com um desvio-padrão de 18,15. Ou seja, perde-se mais metionina nas excretas que nos alimentos pela metodologia da hidrólise convencional, e portanto essa metodologia não deve ser utilizada ao mensurar biodisponibilidade da metionina, conforme demonstrado nas tabelas a seguir. Esta afirmação está embasada, também, na alta taxa de recuperação da metionina pela técnica da peroxidação.

TABELA 1 - Composição em metionina (\% na MS) dos alimentos ${ }^{1}$, segundo a metodologia de análise.

\begin{tabular}{lcccccccc}
\hline & RR & TIM & GT & FTC & FTE & FTH & FTA & FTG \\
\hline Hidrólise $^{2}$ & 0,48 & 0,23 & 0,36 & 0,14 & 0,15 & 0,24 & 0,17 & 0,21 \\
Peroxidação & 0,40 & 0,24 & 0,61 & 0,22 & 0,28 & 0,36 & 0,33 & 0,32 \\
\hline
\end{tabular}

Análises realizadas no laboratório de nutrição da Escola de Veterinária da UFMG.

1: RR = ração-referência, TIM = trigo integral moído, GT = germe de trigo, FTC = farinha de trigo clara, FTE = farinha de trigo escura, FTH = farelo de trigo para uso humano, FTA = farelo de trigo para uso animal, FTG = farelo de trigo grosso. 
Técnica da peroxidação para a determinação de metionina em ...

TABELA 2 - Coeficiente de biodisponibilidade aparente da metionina dos alimentos (\%) segundo a metodologia de análise.

\begin{tabular}{|c|c|c|c|c|c|c|c|c|}
\hline \multirow{3}{*}{ Alimento $^{1}$} & \multicolumn{4}{|c|}{ Metodologia tradicional } & \multicolumn{4}{|c|}{ Alimentação forçada } \\
\hline & \multicolumn{2}{|c|}{ Trat.1 } & \multicolumn{2}{|c|}{ Trat.2 } & \multicolumn{2}{|c|}{ Trat.3 } & \multicolumn{2}{|c|}{ Trat.4 } \\
\hline & Peroxidação & Hidrólise $^{2}$ & Peroxidação & Hidrólise $^{2}$ & Peroxidação & Hidrólise $^{2}$ & Peroxidação & Hidrólise $^{2}$ \\
\hline $\mathrm{RR}$ & $77,18^{b}$ & $97,22^{\mathrm{a}}$ & $73,06^{b}$ & $95,39^{\mathrm{a}}$ & $58,16^{b}$ & $86,15^{\mathrm{a}}$ & $27,32^{b}$ & $83,50^{\mathrm{a}}$ \\
\hline TIM & $76,37^{\mathrm{b}}$ & $94,77^{\mathrm{a}}$ & $68,95^{\mathrm{b}}$ & $91,71^{\mathrm{a}}$ & $45,05^{b}$ & $73,35^{\mathrm{a}}$ & $17,91^{\mathrm{b}}$ & $60,69^{\mathrm{a}}$ \\
\hline GT & $79,59^{b}$ & $92,95^{\mathrm{a}}$ & $84,12^{b}$ & $91,64^{\mathrm{a}}$ & $73,90^{\mathrm{a}}$ & $68,64^{\mathrm{b}}$ & $59,07^{\mathrm{b}}$ & $79,82^{\mathrm{a}}$ \\
\hline FTC & $77,01^{b}$ & $93,67^{a}$ & $65,03^{b}$ & $90,66^{\mathrm{a}}$ & $65,18^{\mathrm{a}}$ & $53,90^{\mathrm{b}}$ & $3,51^{\mathrm{b}}$ & $37,09^{\mathrm{a}}$ \\
\hline FTE & $78,10^{\mathrm{b}}$ & $90,70^{\mathrm{a}}$ & $70,23^{b}$ & $91,48^{\mathrm{a}}$ & $44,52^{\mathrm{a}}$ & $55,35^{\mathrm{a}}$ & $28,02^{b}$ & $56,64^{\mathrm{a}}$ \\
\hline FTH & $49,88^{\mathrm{b}}$ & $93,14^{\mathrm{a}}$ & $63,51^{\mathrm{b}}$ & $88,41^{\mathrm{a}}$ & $55,05^{\mathrm{a}}$ & $70,18^{\mathrm{a}}$ & $7,70^{\mathrm{b}}$ & $59,44^{\mathrm{a}}$ \\
\hline FTA & $47,27^{b}$ & $84,52^{\mathrm{a}}$ & $61,54^{\mathrm{b}}$ & $91,49^{\mathrm{a}}$ & $33,20^{b}$ & $51,11^{\mathrm{a}}$ & $5,47^{\mathrm{b}}$ & $44,37^{\mathrm{a}}$ \\
\hline FTG & $57,59^{b}$ & $88,33^{\mathrm{a}}$ & $66,51^{\mathrm{b}}$ & $88,87^{a}$ & $44,82^{\mathrm{a}}$ & $61,01^{\mathrm{a}}$ & $21,17^{\mathrm{b}}$ & $62,87^{\mathrm{a}}$ \\
\hline
\end{tabular}

Valores na mesma linha, seguidos de letras distintas, para cada tratamento, diferem entre si pelo teste $\mathrm{F}(\mathrm{P}<0,05)$.

1: $\mathrm{RR}=$ ração-referência, $\mathrm{TIM}=$ trigo integral moído, GT = germe de trigo, FTC = farinha de trigo clara, FTE $=$ farinha de trigo escura, FTH = farelo de trigo para uso humano, FTA = farelo de trigo para uso animal, FTG = farelo de trigo grosso.

2: Valores obtidos por Borges et al. (1999).

Na Tabela 2 apresentam-se os coeficientes de biodisponibilidade aparente da metionina dos alimentos comparando as duas metodologias analíticas. Percebe-se que os coeficientes de biodisponibilidade são afetados pelo método de análise $(\mathrm{P}<0,05)$, não devendo-se utilizar a técnica de hidrólise convencional para determinar coeficientes de biodisponibilidade aparente.

Na metodologia tradicional (tratamento 1 e 2), a biodisponibilidade aparente da metionina obtida por peroxidação foi significativamente diferente da obtida por hidrólise convencional para todos os alimentos $(\mathrm{P}<0,05)$, mostrando valores altos de biodisponibilidade dos alimentos ao se utilizar a técnica de hidrólise convencional.

$\mathrm{Na}$ metodologia da alimentação forçada, com aves intactas, (tratamento 3) as diferenças não foram constantes segundo a técnica de análise $(\mathrm{P}<0,05)$, mostrando alguns valores superestimados de biodisponibilidade aparente da metionina na hidrólise ácida. Os coeficientes de biodisponibilidade aparente da farinha de trigo escura, do farelo de trigo para uso humano e do farelo de trigo grosso não diferiram segundo a técnica de análise $(\mathrm{P}>0,05)$, sugerindo que os alimentos não seguem o mesmo padrão na proporção de perda de metionina pela hidrólise convencional. O uso de alimentos puros ao invés do uso de percentagem de substituição na ração-referência pode ter favorecido a aproximação dos valores de biodisponibilidade nesses alimentos. Pode ser que alguma substância presente nesses alimentos proteja quimicamente a metionina da ação do ácido clorídrico, como lipídeos, ou substâncias presentes na ração-referência possa facilitar a quebra da metionina na hidrólise.

Como descrito anteriormente, os maiores valores de biodisponibilidade aparente da metionina encontrados ao se utilizar a hidrólise convencional, podem ser explicados por uma maior perda de metionina na hidrólise da excreta do que na hidrólise dos alimentos.

Nas aves cecectomizadas as diferenças entre as técnicas foram maiores e constantes $(\mathrm{P}<0,05)$, pois essas aves excretam mais metionina, que é dosada sem perdas, ao se utilizar a peroxidação.

Os dados de biodisponibilidade verdadeira (tabela 3 ) divergiram segundo a técnica analítica $(P<0,05)$ em todos os alimentos na metodologia tradicional (tratamentos 1 e 2) e na maioria dos alimentos na metodologia da alimentação forçada (tratamento 3 e 4). 
TABELA 3 - Coeficiente de biodisponibilidade verdadeira da metionina dos alimentos (\%),segundo a metodologia de análise.

\begin{tabular}{|c|c|c|c|c|c|c|c|c|}
\hline \multirow{3}{*}{ Alimento $^{1}$} & \multicolumn{4}{|c|}{ Metodologia tradicional } & \multicolumn{4}{|c|}{ Alimentação forçada } \\
\hline & \multicolumn{2}{|c|}{ Trat.1 } & \multicolumn{2}{|c|}{ Trat.2 } & \multicolumn{2}{|c|}{ Trat.3 } & \multicolumn{2}{|c|}{ Trat.4 } \\
\hline & Peroxidação & Hidrólise $^{2}$ & Peroxidação & Hidrólise $^{2}$ & Peroxidação & Hidrólise $^{2}$ & Peroxidação & $\begin{array}{c}\text { Hidróli- } \\
\text { se }^{2}\end{array}$ \\
\hline $\mathrm{RR}$ & $81,34^{\mathrm{b}}$ & $98,12^{\mathrm{a}}$ & $74,33^{b}$ & $95,76^{\mathrm{a}}$ & $82,64^{\mathrm{b}}$ & $97,11^{\mathrm{a}}$ & $61,19^{b}$ & $94,59^{a}$ \\
\hline TIM & $81,50^{\mathrm{b}}$ & $96,03^{\mathrm{a}}$ & $70,43^{b}$ & $92,20^{\mathrm{a}}$ & $86,41^{\mathrm{b}}$ & $97,17^{\mathrm{a}}$ & $75,13^{\mathrm{a}}$ & $84,79^{a}$ \\
\hline GT & $83,06^{b}$ & $94,39^{\mathrm{a}}$ & $84,58^{b}$ & $92,01^{\mathrm{a}}$ & $90,05^{\mathrm{a}}$ & $83,19^{b}$ & $81,42^{b}$ & $94,54^{\mathrm{a}}$ \\
\hline FTC & $83,75^{b}$ & $95,48^{\mathrm{a}}$ & $67,46^{\mathrm{b}}$ & $91,54^{\mathrm{a}}$ & $111,50^{\mathrm{a}}$ & $91,78^{\mathrm{b}}$ & $67,60^{\mathrm{a}}$ & $75,41^{\mathrm{a}}$ \\
\hline FTE & $83,57^{\mathrm{b}}$ & $92,39^{\mathrm{a}}$ & $71,78^{\mathrm{b}}$ & $92,14^{\mathrm{a}}$ & $80,03^{b}$ & $90,34^{\mathrm{a}}$ & $77,15^{\mathrm{a}}$ & $92,05^{\mathrm{a}}$ \\
\hline FTH & $55,50^{\mathrm{b}}$ & $94,87^{\mathrm{a}}$ & $64,93^{\mathrm{b}}$ & $89,02^{\mathrm{a}}$ & $82,07^{\mathrm{a}}$ & $92,40^{\mathrm{a}}$ & $45,09^{b}$ & $81,92^{\mathrm{a}}$ \\
\hline FTA & $53,21^{\mathrm{b}}$ & $86,27^{\mathrm{a}}$ & $62,89^{\mathrm{b}}$ & $92,03^{a}$ & $64,45^{\mathrm{b}}$ & $75,11^{\mathrm{a}}$ & $48,70^{\mathrm{b}}$ & $82,20^{a}$ \\
\hline FTG & $62,78^{\mathrm{b}}$ & $90,08^{\mathrm{a}}$ & $67,61^{\mathrm{b}}$ & $89,44^{\mathrm{a}}$ & $74,01^{\mathrm{b}}$ & $86,59^{a}$ & $61,54^{\mathrm{b}}$ & $88,76^{a}$ \\
\hline
\end{tabular}

Valores na mesma linha, seguidos de letras distintas, para cada tratamento, diferem entre si pelo teste $\mathrm{F}(\mathrm{P}<0,05)$.

1: RR = ração-referência, TIM = trigo integral moído, GT = germe de trigo, FTC = farinha de trigo clara, FTE = farinha de trigo escura, FTH = farelo de trigo para uso humano, FTA = farelo de trigo para uso animal, FTG = farelo de trigo grosso.

2: Valores obtidos por Borges et al. (1999).

Likuski \& Dorrell (1978), ao avaliar a biodisponibilidade verdadeira de várias amostras de farelo de milho e farelo de soja pela metodologia da alimentação forçada, encontraram valores de biodisponibilidade verdadeira acima de $100 \%$ para o triptofano, cistina, metionina, lisina, tirosina, histidina e serina. Segundo os pesquisadores, isto pode ter ocorrido devido às pequenas concentrações desses nutrientes nos alimentos e na excreta. Da mesma maneira, foi encontrada biodisponibilidade verdadeira da metionina acima de $100 \%$ na farinha de trigo clara em frangos intactos, ao se utilizar a metodologia da alimentação forçada (tratamento 3), mostrando erros nessa metodologia. A biodisponibilidade da matéria seca desse alimento foi alta (92,03\%), o que pode ter gerado maior catabolismo da metionina e transformações dessa pelos microorganismos presentes nos cecos, além do volume de excreta ter sido extremamente baixo. Nesse caso, o valor de metionina encontrado na excreta das aves que consumiram os alimentos-teste pode ter sido menor que o valor de metionina excretado pelas aves em jejum, portanto, o valor da biodisponibilidade verdadeira desse alimento pode ter sido maior que $100 \%$.

Como vimos nos dados anteriores deste trabalho associado aos valores da taxa de recuperação da metionina, a quebra da metionina pelo ácido clorídrico na excreta é alta, o que faz com que a perda endógena dosada pela técnica da hidrólise convencional seja pequena. No caso da metionina analisada pela metodologia de peroxidação, seguida de hidrólise, a perda endógena será alta, pois não haverá quebra de metionina. Dessa forma, os valores de biodisponibilidade verdadeira da metionina se aproximam ao se compararem técnicas analíticas.

Na Tabela 4 encontram-se os valores de metionina digestível aparente dos alimentos segundo a metodologia de análise.

Na ração-referência, foi encontrado maior teor e maior biodisponibilidade de metionina quando se utilizou a técnica de hidrólise convencional $(\mathrm{P}<0,05)$; por isso, $\mathrm{o}$ valor de metionina digestível aparente encontrado pela hidrólise foi superior ao encontrado pela peroxidação.

No trigo integral moído os valores de metionina digestível aparente foram maiores na hidrólise convencional $(P<0,05)$, pois os teores encontrados foram semelhantes entre as metodologias de análise (tabela 1), porém os coeficientes de biodisponibilidade aparente foram maiores quando se utilizou a hidrólise ácida (tabela 2).

Com relação aos outros alimentos, os valores de metionina digestível aparente se aproximam segundo a técnica de análise pois os alimentos apresentam ao mesmo tempo menores teores de metionina com maiores coeficientes de biodisponibilidade aparente ao se utilizar a hidrólise convencional. Dessa forma, pode-se até encontrar valores estatisticamente semelhantes entre as duas técnicas.

Na Tabela 5 encontram-se os valores de metionina digestível verdadeira dos alimentos segundo a metodologia de análise. 
Técnica da peroxidação para a determinação de metionina em ...

TABELA 4 - Valores de metionina digestível aparente dos alimentos (\%) segundo a metodologia de análise.

\begin{tabular}{|c|c|c|c|c|c|c|c|c|}
\hline \multirow{3}{*}{ Alimento $^{1}$} & \multicolumn{4}{|c|}{ Metodologia tradicional } & \multicolumn{4}{|c|}{ Alimentação forçada } \\
\hline & \multicolumn{2}{|c|}{ Trat.1 } & \multicolumn{2}{|c|}{ Trat.2 } & \multicolumn{2}{|c|}{ Trat.3 } & \multicolumn{2}{|c|}{ Trat.4 } \\
\hline & Peroxidação & Hidrólise $^{2}$ & Peroxidação & Hidrólise $^{2}$ & Peroxidação & Hidrólise $^{2}$ & Peroxidação & Hidrólise $^{2}$ \\
\hline $\mathrm{RR}$ & $0,31^{\mathrm{b}}$ & $0,47^{\mathrm{a}}$ & $0,29^{\mathrm{b}}$ & $0,46^{\mathrm{a}}$ & $0,23^{\mathrm{b}}$ & $0,41^{\mathrm{a}}$ & $0,11^{\mathrm{b}}$ & $0,40^{\mathrm{a}}$ \\
\hline TIM & $0,19^{\mathrm{b}}$ & $0,22^{\mathrm{a}}$ & $0,17^{\mathrm{b}}$ & $0,21^{\mathrm{a}}$ & $0,11^{\mathrm{b}}$ & $0,17^{\mathrm{a}}$ & $0,02^{\mathrm{b}}$ & $0,14^{\mathrm{a}}$ \\
\hline GT & $0,47^{\mathrm{a}}$ & $0,33^{\mathrm{b}}$ & $0,47^{\mathrm{a}}$ & $0,33^{b}$ & $0,45^{\mathrm{a}}$ & $0,25^{b}$ & $0,36^{\mathrm{a}}$ & $0,29^{b}$ \\
\hline FTC & $0,17^{\mathrm{a}}$ & $0,13^{\mathrm{b}}$ & $0,15^{\mathrm{a}}$ & $0,13^{\mathrm{b}}$ & $0,14^{\mathrm{a}}$ & $0,08^{\mathrm{b}}$ & $0,03^{\mathrm{a}}$ & $0,05^{\mathrm{a}}$ \\
\hline FTE & $0,22^{\mathrm{a}}$ & $0,14^{\mathrm{b}}$ & $0,20^{\mathrm{a}}$ & $0,14^{\mathrm{b}}$ & $0,12^{\mathrm{a}}$ & $0,08^{b}$ & $0,04^{\mathrm{a}}$ & $0,08^{\mathrm{a}}$ \\
\hline FTH & $0,24^{\mathrm{a}}$ & $0,22^{\mathrm{b}}$ & $0,25^{\mathrm{a}}$ & $0,21^{\mathrm{b}}$ & $0,20^{\mathrm{a}}$ & $0,17^{\mathrm{a}}$ & $0,10^{\mathrm{a}}$ & $0,14^{\mathrm{a}}$ \\
\hline FTA & $0,23^{\mathrm{a}}$ & $0,19^{\mathrm{b}}$ & $0,22^{\mathrm{a}}$ & $0,19^{\mathrm{b}}$ & $0,13^{\mathrm{a}}$ & $0,11^{\mathrm{b}}$ & $0,00^{\mathrm{b}}$ & $0,13^{\mathrm{a}}$ \\
\hline FTG & $0,21^{\mathrm{a}}$ & $0,14^{\mathrm{b}}$ & $0,24^{\mathrm{a}}$ & $0,16^{\mathrm{b}}$ & $0,15^{\mathrm{a}}$ & $0,08^{\mathrm{b}}$ & $0,04^{\mathrm{b}}$ & $0,09^{\mathrm{a}}$ \\
\hline
\end{tabular}

Valores na mesma linha, seguidos de letras distintas, para cada tratamento, diferem entre si pelo teste $\mathrm{F}(\mathrm{P}<0,05)$.

1: $\mathrm{RR}=$ ração-referência, $\mathrm{TIM}=$ trigo integral moído, GT = germe de trigo, FTC = farinha de trigo clara, FTE = farinha de trigo escura, FTH = farelo de trigo para uso humano, FTA = farelo de trigo para uso animal, FTG = farelo de trigo grosso.

2: Valores obtidos por Borges et al. (1999).

TABELA 5 - Valores de metionina digestível verdadeira dos alimentos(\%) segundo a metodologia de análise.

\begin{tabular}{|c|c|c|c|c|c|c|c|c|}
\hline \multirow{3}{*}{ Alimento $^{1}$} & \multicolumn{4}{|c|}{ Metodologia tradicional } & \multicolumn{4}{|c|}{ Alimentação forçada } \\
\hline & \multicolumn{2}{|c|}{ Trat.1 } & \multicolumn{2}{|c|}{ Trat.2 } & \multicolumn{2}{|c|}{ Trat.3 } & \multicolumn{2}{|c|}{ Trat.4 } \\
\hline & Peroxidação & Hidrólise $^{2}$ & Peroxidação & Hidrólise $^{2}$ & Peroxidação & Hidrólise $^{2}$ & Peroxidação & Hidrólise $^{2}$ \\
\hline $\mathrm{RR}$ & $0,33^{b}$ & $0,47^{\mathrm{a}}$ & $0,30^{\mathrm{b}}$ & $0,46^{\mathrm{a}}$ & $0,33^{b}$ & $0,47^{\mathrm{a}}$ & $0,25^{b}$ & $0,45^{\mathrm{a}}$ \\
\hline TIM & $0,20^{\mathrm{a}}$ & $0,22^{\mathrm{a}}$ & $0,18^{\mathrm{a}}$ & $0,21^{\mathrm{a}}$ & $0,21^{\mathrm{b}}$ & $0,22^{\mathrm{a}}$ & $0,16^{\mathrm{b}}$ & $0,20^{\mathrm{a}}$ \\
\hline GT & $0,50^{\mathrm{a}}$ & $0,34^{\mathrm{b}}$ & $0,48^{\mathrm{a}}$ & $0,33^{b}$ & $0,55^{\mathrm{a}}$ & $0,30^{\mathrm{b}}$ & $0,50^{\mathrm{a}}$ & $0,34^{\mathrm{b}}$ \\
\hline FTC & $0,18^{\mathrm{a}}$ & $0,13^{\mathrm{b}}$ & $0,15^{\mathrm{a}}$ & $0,13^{b}$ & $0,24^{\mathrm{a}}$ & $0,13^{b}$ & $0,17^{\mathrm{a}}$ & $0,11^{\mathrm{b}}$ \\
\hline FTE & $0,23^{a}$ & $0,14^{\mathrm{b}}$ & $0,20^{\mathrm{a}}$ & $0,14^{\mathrm{b}}$ & $0,22^{\mathrm{a}}$ & $0,14^{\mathrm{b}}$ & $0,17^{a}$ & $0,14^{\mathrm{a}}$ \\
\hline FTH & $0,26^{a}$ & $0,23^{b}$ & $0,26^{a}$ & $0,21^{\mathrm{a}}$ & $0,30^{\mathrm{a}}$ & $0,22^{b}$ & $0,23^{\mathrm{a}}$ & $0,20^{\mathrm{a}}$ \\
\hline FTA & $0,22^{\mathrm{a}}$ & $0,19^{b}$ & $0,22^{\mathrm{a}}$ & $0,19^{b}$ & $0,20^{\mathrm{a}}$ & $0,18^{b}$ & $0,13^{\mathrm{a}}$ & $0,19^{\mathrm{a}}$ \\
\hline FTG & $0,25^{a}$ & $0,15^{b}$ & $0,24^{a}$ & $0,16^{\mathrm{b}}$ & $0,25^{a}$ & $0,13^{b}$ & $0,17^{a}$ & $0,14^{\mathrm{a}}$ \\
\hline
\end{tabular}

Valores na mesma linha, seguidos de letras distintas, para cada tratamento, diferem entre si pelo teste $\mathrm{F}(\mathrm{P}<0,05)$.

1: $\mathrm{RR}=$ ração-referência, TIM = trigo integral moído, GT = germe de trigo, FTC = farinha de trigo clara, $\mathrm{FTE}=$ farinha de trigo escura, FTH = farelo de trigo para uso humano, FTA = farelo de trigo para uso animal, FTG = farelo de trigo grosso.

2: Valores obtidos por Borges et al. (1999). 
Foram encontrados valores maiores de metionina digestível verdadeira na ração-referência e no trigo integral moído, e menores ou equivalentes nos outros alimentos testados quando se utilizou a hidrólise convencional $(\mathrm{P}<0,05)$, seguindo o mesmo princípio dos valores de metionina digestível aparente.

Os valores de metionina digestível verdadeira dos alimentos também não devem ser obtidos pela técnica de hidrólise convencional devido aos erros tanto nos valores absolutos de metionina presentes nos alimentos quanto nos coeficientes de biodisponibilidade verdadeira.

\section{CONCLUSÕES}

Sob as condições experimentais em que se realizou a pesquisa, pode ser concluído que:

a) Os valores absolutos de metionina em trigo, seus produtos e excretas de aves não podem ser determinados pela técnica de hidrólise ácida devido à grande perda deste aminoácido na hidrólise.

b) Os valores de metionina digestível e coeficientes de biodisponibilidade aparente e verdadeira também não devem ser analisados pela hidrólise, pois a percentagem de perda da metionina nas excretas é diferente da percentagem de perda da metionina nos alimentos testados.

c) A peroxidação com ácido perfórmico seguida de hidrólise é o mais eficaz método de análise de metionina, devido à sua alta taxa de recuperação.

\section{REFERÊNCIAS BIBLIOGRÁFICAS}

ALBINO, L. T. F. Sistemas de avaliação nutricional de alimentos e suas aplicações na formulação de rações para frangos de corte. 1991.55 f. Tese (Doutorado em Zootecnia) - Universidade Federal de Viçosa, Viçosa, 1991.

BORGES, F. M. O. Determinação dos valores energéticos e dos aminoácidos digestíveis do grão de trigo e seus subprodutos para frangos de corte. 1999. $118 \mathrm{f}$. Tese (Doutorado em Ciência Animal) - Escola de veterinária, Universidade Federal de Minas Gerais, Belo Horizonte, 1999.
CUNNIFF, P. (Ed.). Official methods of analysis of AOAC International. 16. ed. Arlington: AOAC International, 1995. v. 1.

KESSLER, J. W.; NGUYEN, T. H.; THOMAS, O. P. The amino acid excretion values in intact and cecoctomized negative control roosters used for determining metabolic plus endogenous urinary losses. Poultry Science, Champaign, v. 60, n. 8, p. 1576-1577, 1981.

LIKUSKI, H. J. A.; DORRELL, H. G. A bioassay for rapid determinations of amino acid availability values. Poultry Science, Champaign, v. 10, n. 57, p. 16581660, 1978.

LLAMES, R. C.; FONTAINE, J. Determination of amino acids in feeds:Collaborative study. Journal of AOAC International, Arlington, v. 77, n. 6, p. 13621402, 1994.

MUZTAR, A. J.; SLINGER, S. J. Bioavailable amino acids in corn and alfafa as measured by applying the true metabolizable energy assay. Poultry Science, Champaign, v. 12, n. 59, p. 1873-1877, 1977.

PUPA, J. M. R. et al. Cecectomia em galos sob anestesia local e incisão abdominal. Arquivo Brasileiro de Medicina Veterinária e Zootecnia, Belo Horizonte, v. 50, p. 531-535, 1998.

ROSTAGNO, H. S. et al. Composição de alimentos e exigências nutricionais de aves e suínos. 19. ed. Viçosa: UFV, 1985. 59 p.

SIBBALD, I. R. A bioassay for true metabolizable energy in feedingstuffs. Poultry Science, Champaign, n. 55, p. 303-308, 1976.

SLUMP, P.; BOSS, D. K. Determination of methionine in feed concentrates. Poultry Science, Champaign, $n$. 64, p. 705-707, 1985.

WILLIAMS, A. P. Amino acids in farm animals. In: . Edinburgh: the scotish agricultural college. [S.l.: s.n.], 1994. p. 11-36. 